\title{
Landscape analysis of the family planning situation in Pakistan-District profile: Sukkur
}

Population Council

Follow this and additional works at: https://knowledgecommons.popcouncil.org/departments_sbsr-rh

Part of the Demography, Population, and Ecology Commons, Family, Life Course, and Society Commons, International Public Health Commons, Maternal and Child Health Commons, and the Women's Health Commons How does access to this work benefit you? Let us know!

\section{Recommended Citation}

"Landscape analysis of the family planning situation in Pakistan-District profile: Sukkur." Islamabad: Population Council, 2016. 


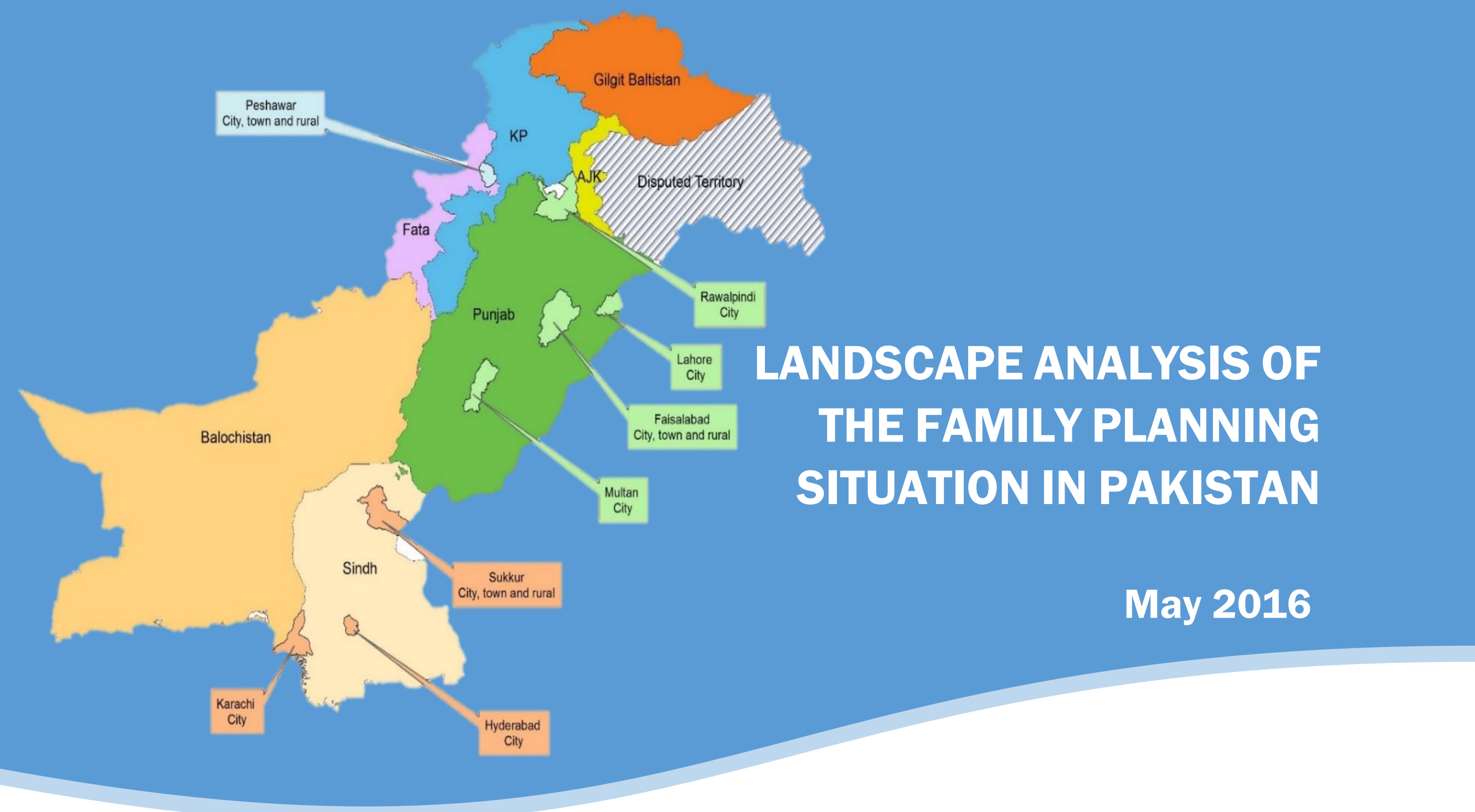

\section{DISTRICT PROFILE: SUKKUR}

BILL \& MELINDA

GATES foundation
POPULATION COUNCIL

Ideas. Evidence. Impact. 


\section{Background}

Sukkur is situated in the northeastern part of the province of Sindh. Its estimated population is 1.5 million. ${ }^{1}$ The district consists of 5 administrative divisions (tehsils/talukas), including New Sukkur, Sukkur City, Saleh Pat, Pano Aqil, and Rohri (Figure 1).

Table 1: Demographics of Sukkur

\begin{tabular}{|c|c|c|c|}
\hline Demographics & Urban & Rural & Overall \\
\hline Total population & 742,000 & 719,000 & $1,461,000$ \\
\hline Women 15-49 & 188,000 & 146,000 & 334,000 \\
\hline MWRA & 122,000 & 110,000 & 232,000 \\
\hline $\begin{array}{l}\text { Literacy rate (10 } \\
\text { years and above) * }\end{array}$ & $71 \%$ & $42 \%$ & $60 \%$ \\
\hline $\mathrm{IMR}^{* *}$ & - & - & 105 \\
\hline $\mathrm{TFR}^{* *}$ & - & - & 4.3 \\
\hline \multicolumn{4}{|c|}{$\begin{array}{l}\text { Source: Sindh Development Statistics 2013, * Pakistan Social and Living } \\
\text { Standards Measurement Survey (PSLMS) 2014-15, ** Multiple Indicator } \\
\text { Cluster Survey Sindh } 2014\end{array}$} \\
\hline
\end{tabular}

The total fertility rate in Sukkur is 4.3 , slightly above Sindh's TFR of 4.0,2 indicating the slower pace of fertility transition in the district. The infant mortality rate in Sukkur is also very high.
Figure 1: Map of Sukkur District

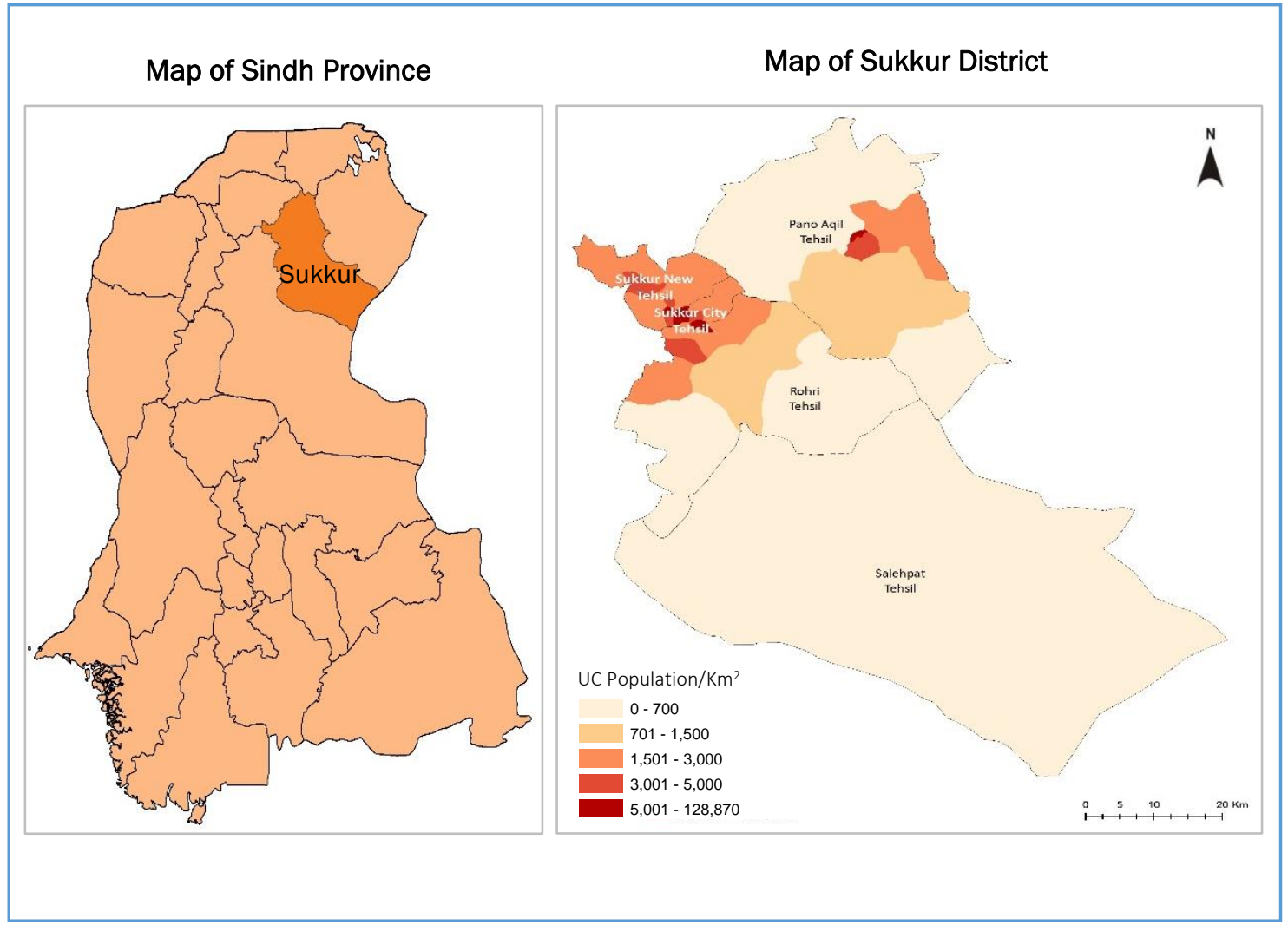

\section{Use of Antenatal and Dellvery Care Services}

While the majority of women in Sukkur sought antenatal health care from skilled health care providers during their last pregnancy $(73 \%),{ }^{3}$ the proportion of women who did not seek antenatal care was higher than most of the other study districts. The proportion of women who sought antenatal health care is higher in urban (75\%) than rural areas (70\%). In both urban and rural areas, the majority sought care from a private hospital or clinic. The most common places of delivery in urban areas are private hospitals or clinics (67\%), but in rural areas, more than two thirds of deliveries take place at home.

1 Estimate based on Sindh Development Statistics 2013

${ }^{3}$ Pakistan Social and Living Standards Measurement Survey (PSLMS) 2014-15

${ }^{2}$ Multiple Indicator Cluster Survey (MICS) Sindh, 2014 


\section{Use of Family Planning}

Contraceptive use among currently married couples in Sukkur district, at 27 percent, ${ }^{4}$ is below the Sindh's average (29\%). However, as Table 2 shows, almost all use is comprised of modern methods (26.9\%), with only a negligible proportion of couples using traditional methods $(0.3 \%)$. Unmet need for family planning is as high as 20.9 percent.

Table 2: Contraceptive use and unmet need

\begin{tabular}{lllll}
\hline & \multicolumn{3}{c}{ Contraceptive Prevalence Rate (CPR) } & \\
\cline { 2 - 4 } District & $\begin{array}{l}\text { Any } \\
\text { Method }\end{array}$ & $\begin{array}{l}\text { Traditional } \\
\text { Methods }\end{array}$ & $\begin{array}{l}\text { Modern } \\
\text { Methods }\end{array}$ & $\begin{array}{c}\text { Unmet } \\
\text { need }\end{array}$ \\
\hline Sukkur & 27.2 & 0.3 & 26.9 & 20.9 \\
\hline
\end{tabular}

Source: Multiple Indicator Cluster Survey (MICS) Sindh 2014

\section{Other Socio-economic Indicators}

The literacy rate (10 years and above) in Sukkur is 60 percent, with very large urban-rural differences (urban $71 \%$, rural $42 \%$ ). Women of reproductive age are even less educated in both urban (60\%) and rural areas (14\%).

The majority of households own a television set (66\%), but urban-rural differences are huge, with 80 percent of urban households owning a TV set compared to only 42 percent of rural households. Mobile or land line phones are owned by the vast majority of households $(91 \%)$, with minor urban-rural differences.

In terms of house building materials, the main material used for roofs is garder (Iron slabs)/T-Iron, which is used by 61 percent of houses in the district, mainly in urban areas (69\%), with the majority of rural houses using wood or bamboo $(52 \%)$. Walls of houses are mainly built of burnt bricks or blocks in urban areas, and mud bricks or mud in rural areas. This indicates middle socio-economic status.

\section{Avallability of Health Facllitles, Pharmacles and LHWs}

During the landscape analysis of family planning, a census of public and private health facilities and pharmacies was carried out in Sukkur district. Figure 2 shows the breakdown of public and private health facilities in urban and rural areas of the district. Overall, private facilities and pharmacies are more numerous in urban areas ( $31 \%$ and $25 \%$, respectively) while LHWs are there in

${ }^{4}$ Multiple Indicator Cluster Survey Sindh 2014 larger numbers in the rural areas (54\%). A good proportion of LHWs is also available in the urban areas (36\%). There are more facilities of the Department of Health (DoH) in rural areas whereas facilities of the People's Primary Healthcare Initiative (PPHI) are present only in the rural areas.

Figure 2: Urban-rural distribution of health facilities and pharmacies in Sukkur by sector, 2016
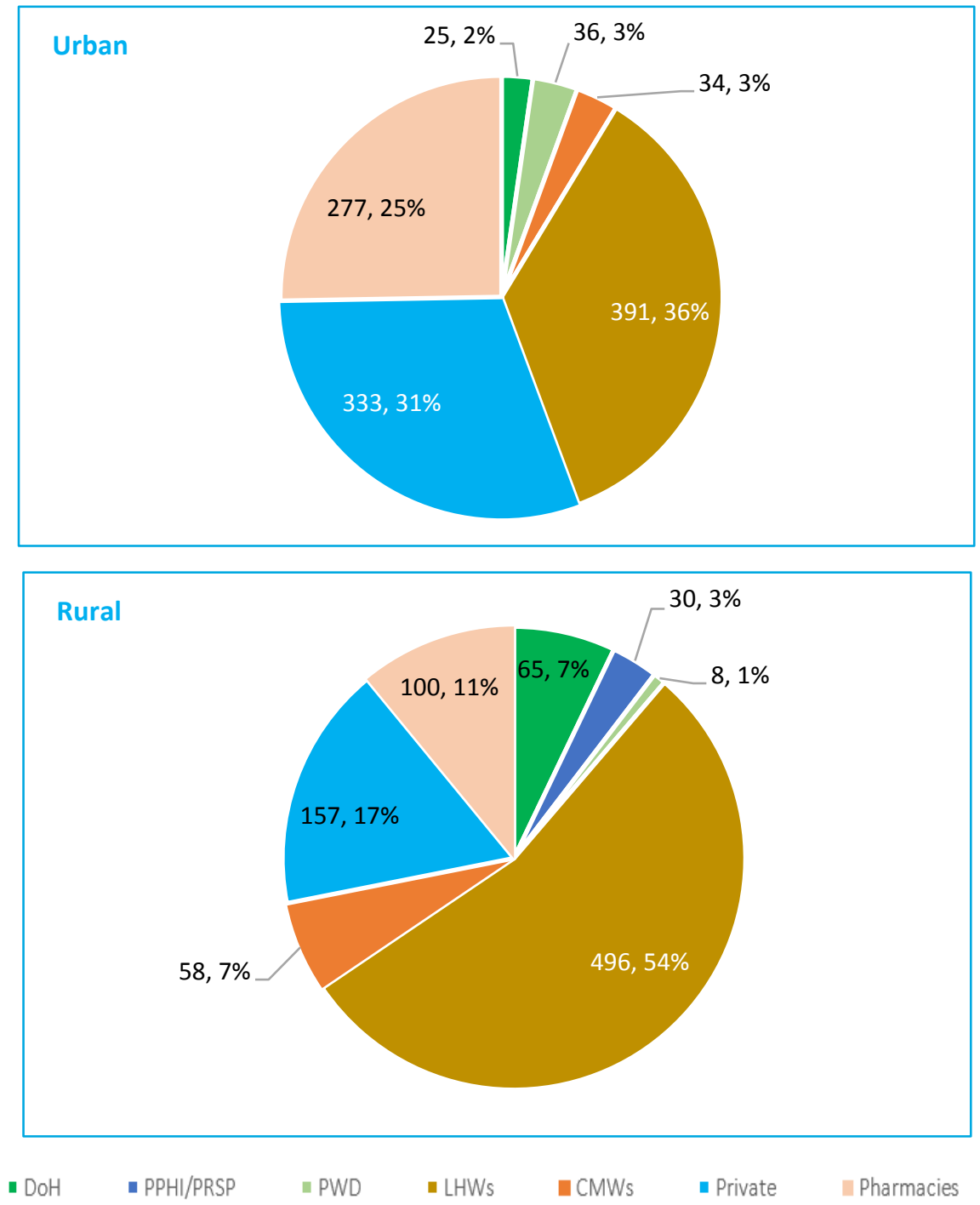


\section{Distribution of Public Health Facilities by Cadre}

Figure 3 shows the distribution of public facilities in urban and rural areas of Sukkur. In urban areas, Family Welfare Centers (FWCs) of the Population Welfare Department (PWD) are present in greater numbers (52\%), with the dispensaries of DoH comprising the next largest category (26\%). In rural areas, dispensaries are higher in number (56\%), followed by facilities of PPHI (29\%).

Figure 3: Cadre-wise urban-rural distribution of static public facilities in Sukkur, 2016
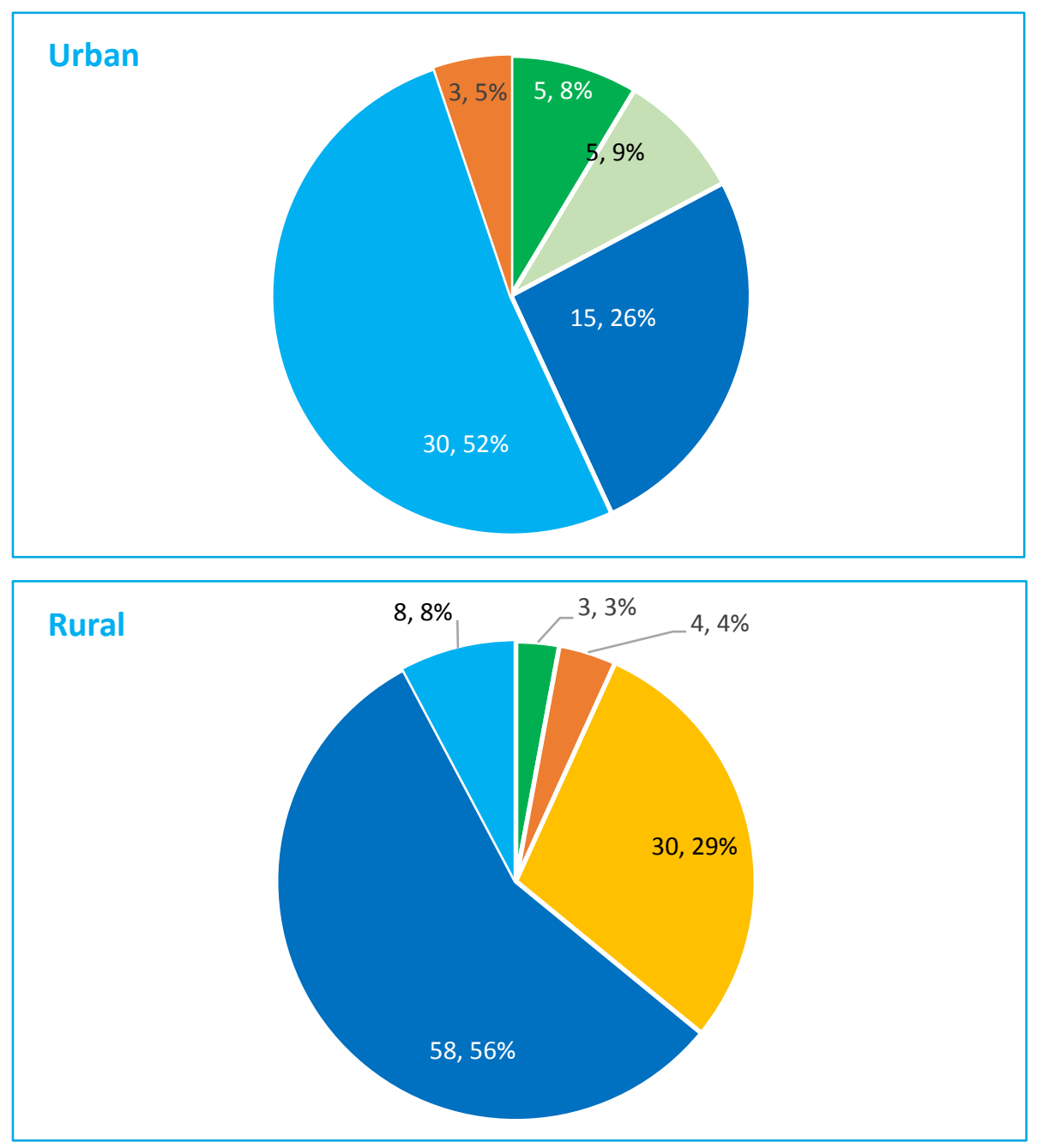

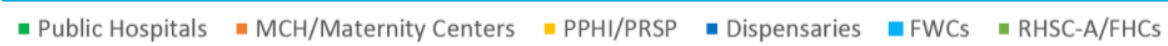

\section{Distribution of Private Facilities by Cadre}

Figure 4 shows distribution of private facilities in urban and rural areas of Sukkur. In urban areas, clinics of male doctors are the most numerous (32\%), followed by clinics of LHV/midwife/nurse clinics (17\%), and homeopath/hakeem clinics (15\%). In rural areas, dispenser clinics are present in the highest number (51\%), followed by clinics of male doctors (24\%), and homeopath/hakeem clinics (17\%).

Figure 4: Cadre-wise urban-rural distribution of private facilities in Sukkur, 2016
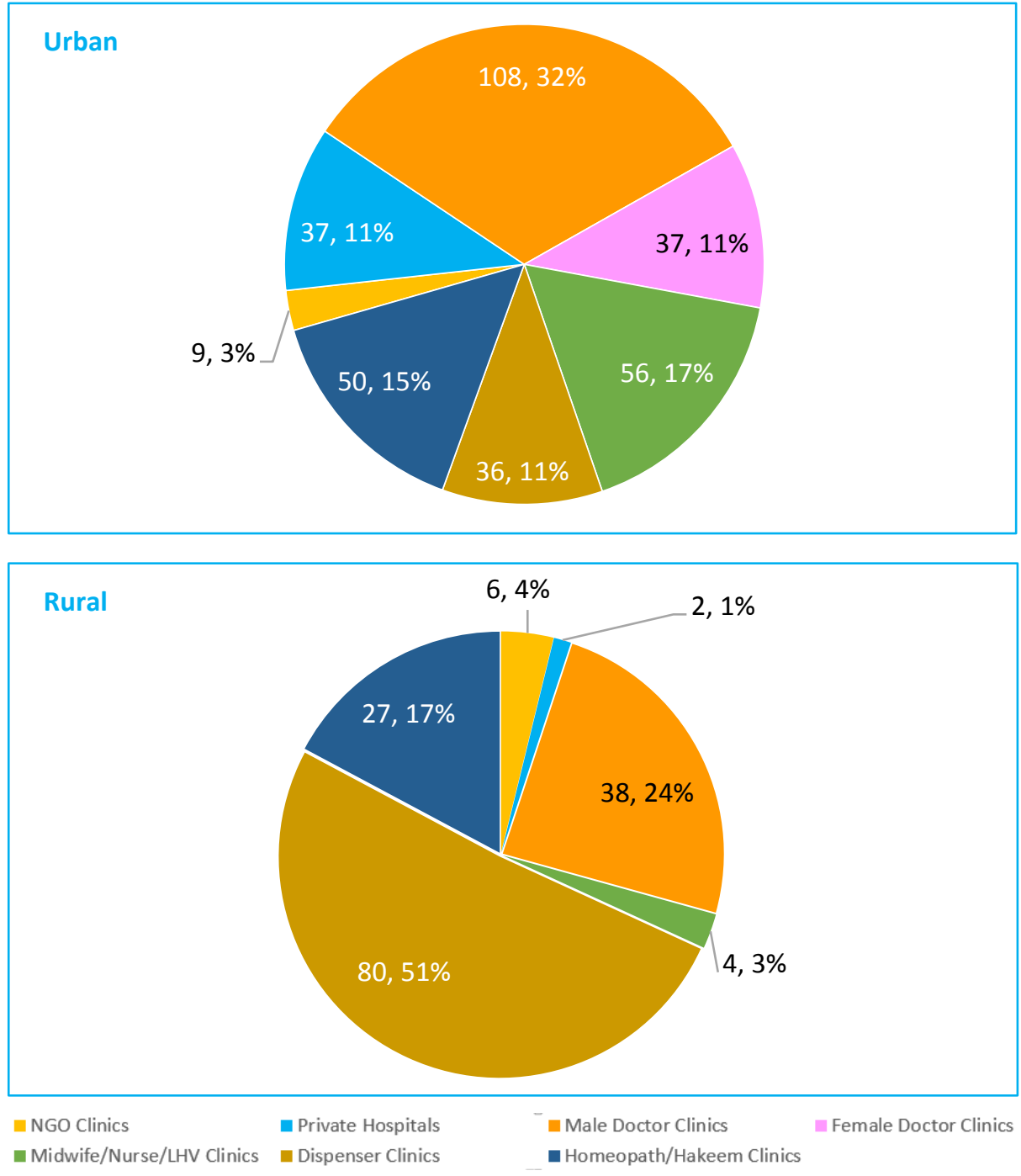


\section{Provision of Specific Family Planning Methods by Sector}

Table 3 shows proportion of different sectors providing specific family planning methods in urban and rural areas of Sukkur. Facilities of DoH are providing mainly condoms, pills, injectables and IUDs but the level of provision is quite low for these as well as the other methods. Facilities of the PWD are fully providing most methods; provision of ECPs, implants and sterilization services is low. LHWs are almost fully providing condoms, pills and the second/subsequent doses of injectables. Notably, this cadre has a huge potential for providing the first dose of injectables and emergency contraceptive pills (ECPs) as well.

Private facilities are considerable in numbers but only a small proportion $(<30 \%)$ are providing any method in both urban and rural areas.

Table 3: Provision of specific family planning methods in Sukkur by sector, \%, 2016

\begin{tabular}{|c|c|c|c|c|c|c|c|c|c|c|c|c|c|c|c|c|c|c|}
\hline \multirow[b]{2}{*}{ Sector } & \multicolumn{2}{|c|}{ Condoms } & \multicolumn{2}{|c|}{ OCPs } & \multicolumn{2}{|c|}{ Injectables } & \multicolumn{2}{|c|}{ IUDs } & \multicolumn{2}{|c|}{ ECPs } & \multicolumn{2}{|c|}{ Implants } & \multicolumn{2}{|c|}{$\begin{array}{c}\text { Female } \\
\text { Sterilization }\end{array}$} & \multicolumn{2}{|c|}{$\begin{array}{c}\text { Male } \\
\text { Sterilization }\end{array}$} & \multicolumn{2}{|c|}{$\begin{array}{c}\text { Number of Facilities/ } \\
\text { Pharmacies }\end{array}$} \\
\hline & U & $R$ & U & $R$ & U & $R$ & $U$ & $\mathrm{R}$ & $\mathrm{U}$ & $\mathbf{R}$ & U & $\mathbf{R}$ & U & $R$ & U & $\mathrm{R}$ & U & $R$ \\
\hline DoH & 48 & 22 & 56 & 25 & 56 & 20 & 40 & 12 & 20 & 8 & 16 & 8 & 8 & 3 & 4 & 0 & 25 & 65 \\
\hline PPHI/PRSP & - & 90 & - & 97 & - & 100 & - & 87 & - & 40 & - & 70 & - & 0 & - & 0 & - & 30 \\
\hline PWD & 90 & 97 & 97 & 100 & 97 & 100 & 92 & 100 & 97 & 63 & 14 & 25 & 8 & 0 & 6 & 0 & 36 & 8 \\
\hline LHWs & 100 & 100 & 100 & 100 & 100 & 100 & NA & NA & NA & NA & NA & NA & NA & NA & NA & NA & 391 & 496 \\
\hline Private & 23 & 11 & 23 & 5 & 28 & 6 & 19 & 2 & 17 & 3 & 4 & 0 & 5 & 0 & 1 & 0 & 333 & 157 \\
\hline Pharmacies & 61 & 61 & 59 & 26 & 43 & 26 & 0 & 0 & 6 & 0 & 0 & 0 & NA & NA & NA & NA & 277 & 100 \\
\hline
\end{tabular}

NA: Not applicable, U: Urban, R: Rural

ECP: emergency contraceptive pill, IUD: intrauterine device, OCP: oral contraceptive pill 


\section{Presence and Provision of FP Services/Methods: A Comparison}

Figures 5, 6 and 7 present pairs of maps showing the presence of public health facilities, private health facilities, and pharmacies, respectively, and actual provision of family planning services/products by each category. Figure 5 shows that, collectively, only 71 percent of the 164 public health facilities present are providing family planning services, although they are all mandated to provide this service.

Figure 5: Proportion of public static facilities providing at least one FP service in Sukkur, 2016
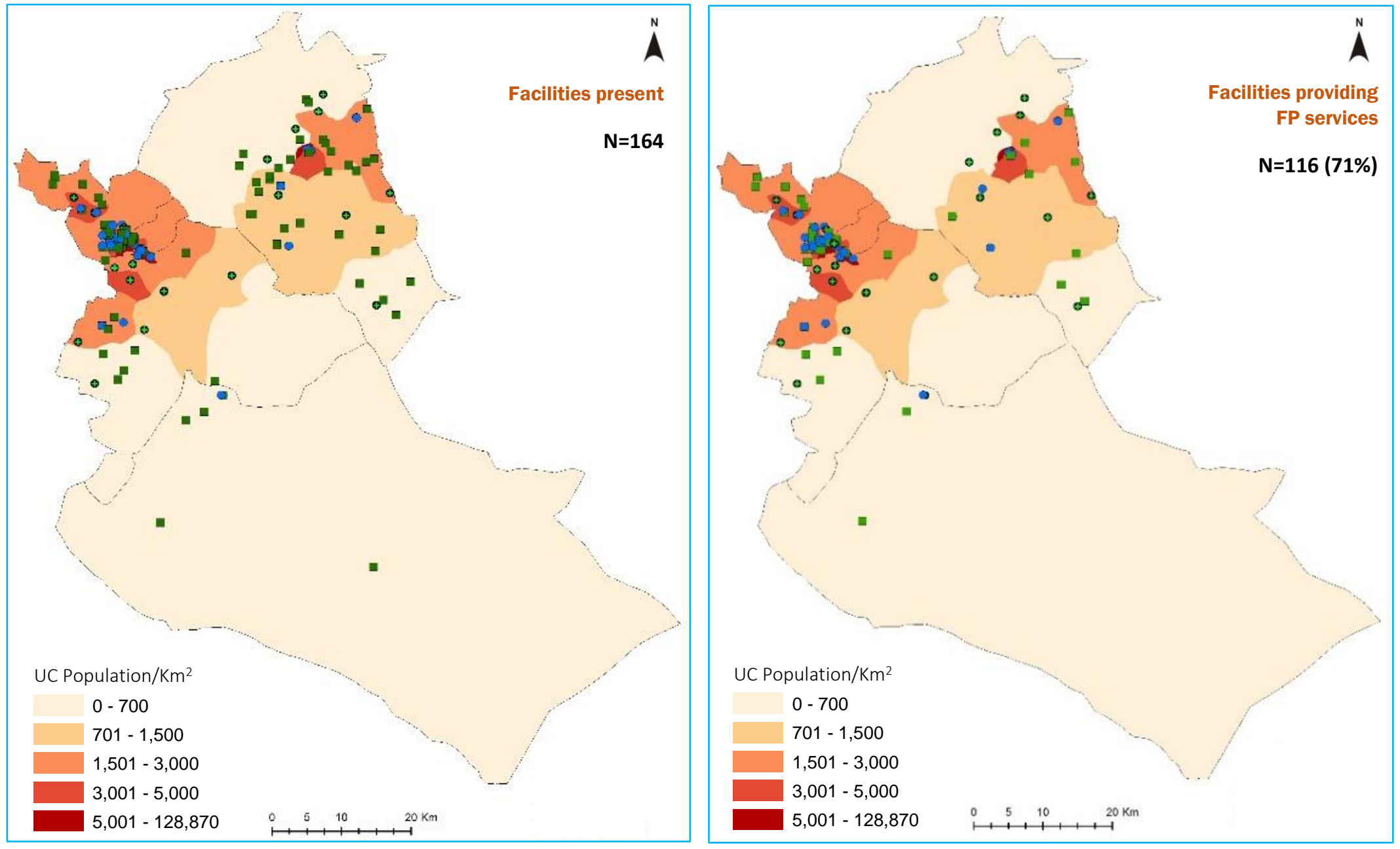

- Department of Health $(\mathrm{DoH})$

- People's Primary Health Care Initiative (PPHI)

- Population Welfare Department (PWD) 


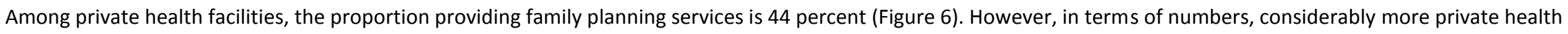
facilities than public facilities are providing family planning services.

Figure 6: Proportion of private health facilities providing at least one FP service in Sukkur, 2016

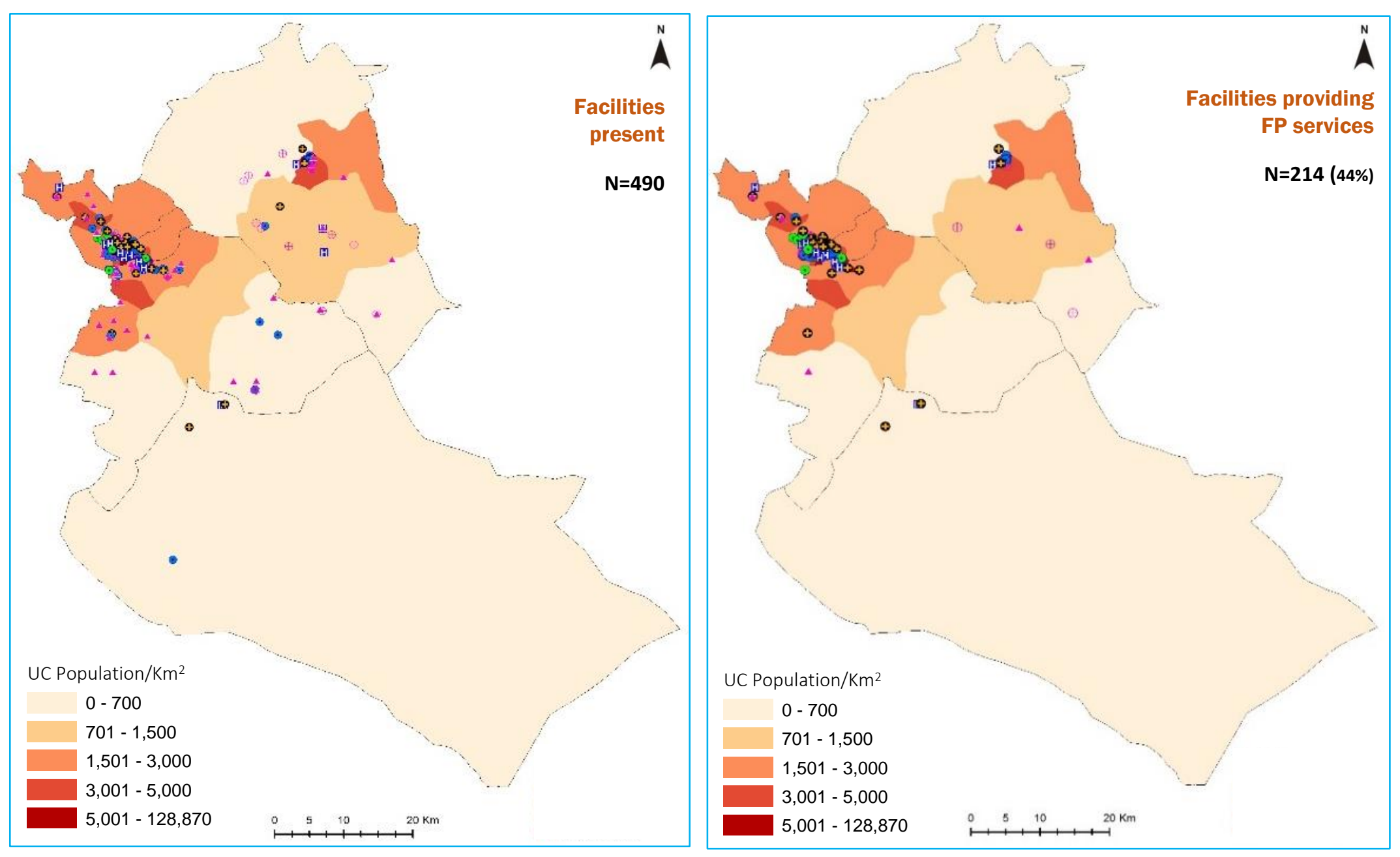

(1) Private Hospitals

- LHV/Nurse/Midwife Clinics

- Male Doctor Clinics

4. Dispenser Clinics

- Female Doctor Clinics

$\oplus$ Homeopath/Hakeem Clinics 
Encouragingly, 70 percent of pharmacies in the district are selling at least one FP product (Figure 7).

Figure 7: Proportion of pharmacies selling at least one FP product in Sukkur, 2016

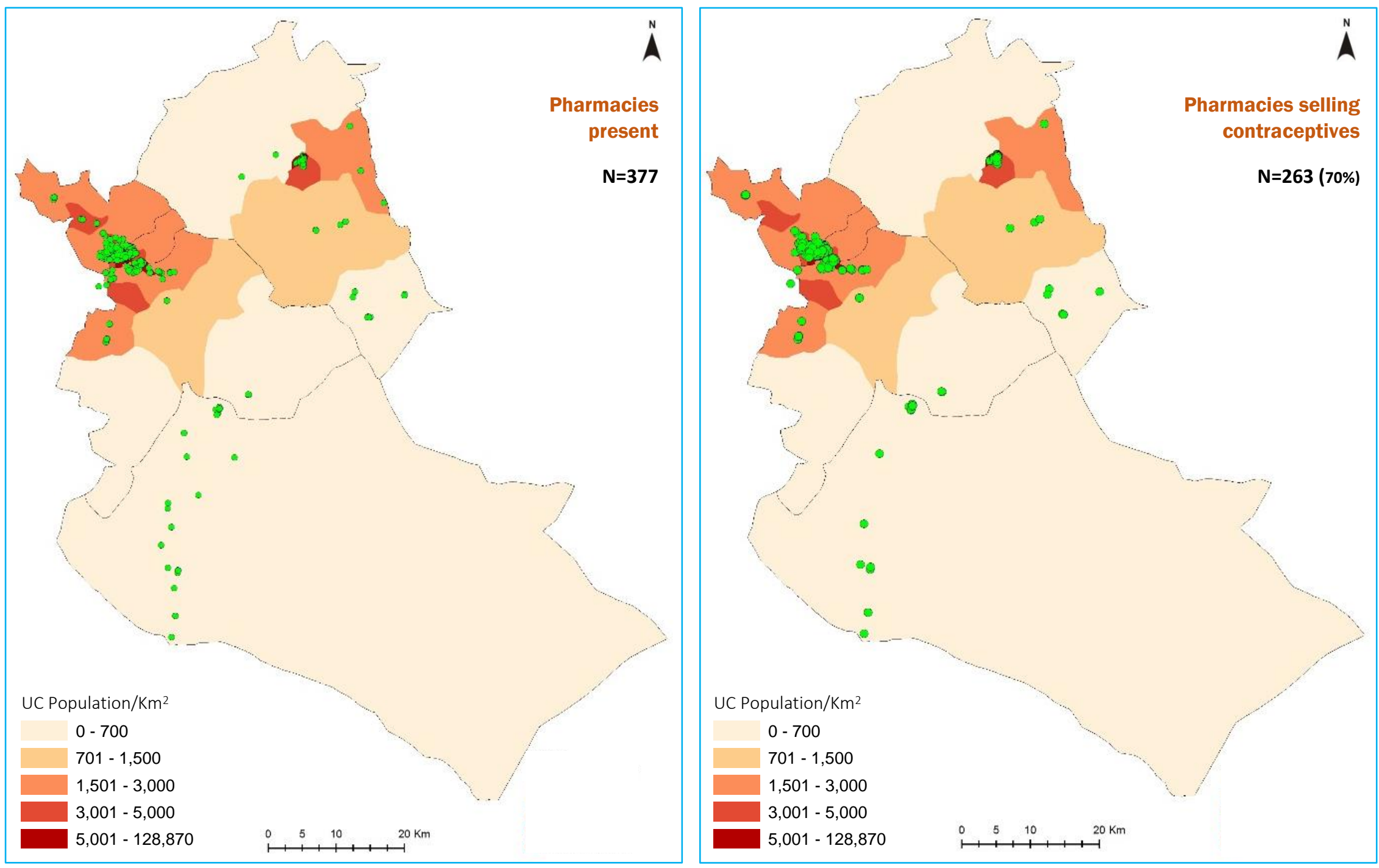




\section{Consumer Perspectives on Barriers to Use of Family Planning}

During the landscape assessment, perspectives of men and women on family planning use were collected in the main city, urban areas, and rural areas of Sukkur through in-depth interviews (IDIs) and focus group discussions (FGDs). For views of men and women in the city, FGDs were conducted in the Kumar Para and New Pindi Railway Quarter communities in Tehsil Sukkur. For rural perspectives, IDIs were conducted in tehsils Rohri and Sukkur, while other urban perspectives were explored in tehsil Panu Akil. The study involved 47 IDIs (34 with women and 13 with men) and 8 FGDs with men and women. A total of 112 men and women participated in these interactions.

Based on respondents' views, four main barriers were identified, including lack of information and services for family planning among men; cost of methods and services, affecting the poor; poor quality of services at public static facilities; and low accessibility of facilities. While the last barrier was felt acutely in rural areas but had a relatively low influence in urban areas, the remaining three were felt strongly in both urban and rural areas. Additionally, there were complaints about the quality of services at camps providing implants in both urban and rural areas.

\section{Lack of information among men in rural and urban areas}

- Men feel embarrassed talking about family planning and consider it inappropriate to discuss it with other men.

- Men have limited opportunities to talk about family planning and therefore do not know where to go for family planning or who to talk to.

"I don't know of any particular place to discuss family planning issues. I don't have any opportunity to discuss this subject." Male, Sukkur rural

"We can talk (among ourselves in waiting area) about family planning, the number of children, what is family planning, etc. only when we go to a hospital, or visit a doctor, or go for the children's polio vaccination. Otherwise, there is no place where we can discuss about family planning." Male, Sukkur rural

- Men want detailed information on family planning methods, such as possible side effects, how they would be managed, and where they can get methods.
Costs of contraceptives and services-a hurdle for rural and urban poor

- Poorer couples depend on the free contraceptives provided by LHWs, but have to manage method and sometimes also travel costs from their own meager resources when the LHW's stocks run out.

"Sometimes we don't have money to buy condoms. We mostly use withdrawal that day because those 20 rupees mean a lot to us. Some days my husband earns, and some days he doesn't. He is a laborer. We buy condoms if we have money; otherwise we use withdrawal." Female, Sukkur rural

- The cost of treatment for any side effects, and the repeated visits involved in such treatment, can also be too much to bear for poorer users.

- Private facilities charge high prices for methods and even for removal of IUDs and implants.

"I can't tell you how hard it was to arrange the money (to pay for treatment of side effects). My husband had to borrow a huge sum from different people, which we still have to pay back. They come every day asking for their money. We live under great stress." Female, Sukkur city

\section{Issues of access for rural couples with no local facilities}

- Rural couples rely mainly on contraceptives provided by LHWs.

- Rural women do not go alone to government hospitals, and female mobility is particularly restricted among Baloch families.

- Method choices in rural areas are restricted to what is locally availablewomen can only use implants and IUDs if a camp is arranged.

- It is hard for women to leave the house and children unattended for long hours.

"My menses stopped six years ago. I am poor, the hospital is far away, and I have no money for treatment or fare. I cannot take my children with me and there is no one here to take care of them." Female, Sukkur city 
Poor quality of services at public facilities

- Service providers at public facilities often do not attend to clients properly and force them to visit their private clinics in the evening where they charge fees.

- Providers can be rude and insulting

- Providers reportedly do not answer questions raised by clients

“They give these brown pills to all patients, that aren't packages, and everybody touches them (It is unhygienic). When we go for an ultrasound, they don't do it properly, don't give a detailed report (picture); they write two words and tell us to leave." Female, Sukkur city

- Users believe there is a gap in the knowledge of service providers, especially regarding implants.

"The doctor told me, 'If you get a 3-month injection, you will stay safe for six months,' but I kept getting the injection every three months, on my own, just to be safe." Female, Sukkur city
Poor quality of care associated with implant camps in urban and rural areas

- Men and women report the following perceptions of camps conducted to provide implants:

- Camps are overcrowded

- Service providers are in a hurry and do not provide proper counseling

- Providers are not skilled for insertion or management of side effects.

- There is no follow-up mechanism after insertion, no contact with static health facilities in the surrounding area, and avenues for removal of implants, should a client want to discontinue, are not available.

- Non-availability of skilled service providers in the vicinity raises the costs of managing side effects of implants, which can be hard to bear.

"Camps have unskilled staff; my implant was inserted in the muscles. I spent 50 to 60 thousand rupees on treatment (having to travel from Sukkur to Karachi) but am still not completely recovered. I think it is better to deliver a child than to use an implant. Using this method has proved too costly for me; I would never recommend it to anyone." Female, Sukkur city 


\section{District specific Donors, Projects and Implementing partners}

\begin{tabular}{|c|c|c|}
\hline Donor & Program/ Project Title & Implementing Partner \\
\hline DFID & Delivering Reproductive Health Results (DRHR), 2012-2017 & $\begin{array}{l}\text { Population Services International (PSI)/ Greenstar Social } \\
\text { Marketing (GSM) } \\
\text { Marie Stopes International: Reproductive Health Franchise } \\
\text { DKT International/Pakistan }\end{array}$ \\
\hline \multirow{2}{*}{$\begin{array}{l}\text { Bill and Melinda } \\
\text { Gates Foundation }\end{array}$} & $\begin{array}{l}\text { Building Blocks for Family Planning in Pakistan - Developing a Costed Implementation } \\
\text { Plan for Sindh and Punjab, 2013-2015 }\end{array}$ & Pathfinder International \\
\hline & $\begin{array}{l}\text { Landscape Analysis of Family Planning in Pakistan, } \\
\text { 2015-2016 }\end{array}$ & Population Council \\
\hline $\begin{array}{l}\text { The David \& Lucile } \\
\text { Packard Foundation }\end{array}$ & Achieving MDG5 - Continuing Momentum, Building Champions, 2012-2015 & Shirkat Gah Women Resource Centre \\
\hline \multirow{5}{*}{ USAID } & DELIVER Project, 2008-2016 & $\begin{array}{l}\text { Planning Commission of Pakistan } \\
\text { Ministry of Health } \\
\text { Provincial and regional departments of health and population } \\
\text { UNFPA } \\
\text { NGOs }\end{array}$ \\
\hline & Family Planning and Reproductive Health Services, 2013-2017 & Marie Stopes Society \\
\hline & Maternal and Child Health Integrated Program (MCHIP), 2013-2017 & Jhpiego \\
\hline & Health Communication, 2014-2019 & $\begin{array}{l}\text { Johns Hopkins University Center for Communication Programs } \\
\text { (JHUCCP) }\end{array}$ \\
\hline & Health System Strengthening & JSI Research \& Training Institute, Inc. \\
\hline \multirow[b]{2}{*}{ UNFPA } & Capacity Building of Female Service Providers Enhanced in Family Planning, 2014-2017 & $\begin{array}{l}\text { Population Welfare Departments } \\
\text { MNCH Programs } \\
\text { LHWs Program }\end{array}$ \\
\hline & $\begin{array}{l}\text { Advocacy for Universal Access to Reproductive Health and to Integrate in Provincial } \\
\text { Health Policies, Plans and Budgetary Frameworks, 2012-2017 }\end{array}$ & $\begin{array}{l}\text { Population Welfare Departments } \\
\text { Population Council } \\
\text { Pathfinder } \\
\text { Ministry of National Health Services, Regulations and } \\
\text { Coordination }\end{array}$ \\
\hline WHO & $\begin{array}{l}\text { Providing Technical Assistance to the Country for the Development of a Unified Care } \\
\text { Providers Manual on FP based on the WHO Handbook on FP }\end{array}$ & $\begin{array}{l}\text { Ministry of National Health Services Coordination and } \\
\text { Regulation } \\
\text { MNCH programs } \\
\text { UNFPA, Population Council, GIZ, USAID, etc. }\end{array}$ \\
\hline $\begin{array}{l}\text { Large Anonymous } \\
\text { Donor (LAD) }\end{array}$ & $\begin{array}{l}\text { Increasing Access to and Use of Long-Term Methods of FP and PAC Services in } \\
\text { Pakistan, 2014-16 }\end{array}$ & Greenstar Social Marketing \\
\hline
\end{tabular}

